\title{
Application of the AJCC 7th edition carcinoma of the eyelid staging system: a medical center pathology based, I5-year review
}

This article was published in the following Dove Press journal:

Clinical Ophthalmology

17 November 2011

Number of times this article has been viewed

\section{Courtney Crawford' \\ Colby Fernelius ${ }^{2}$ \\ Paula Young' \\ Stephen Groo \\ Darryl Ainbinder ${ }^{2}$}

'Blanchfield Army Hospital, Fort Campbell, KY, USA; ${ }^{2}$ Madigan Army

Medical Center, Fort Lewis, WA, USA
Correspondence: Courtney Crawford Blanchfield Army Hospital,

Ophthalmology Service, Department of Surgery, 650 Joel Drive, Fort Campbell,

KY 42223-53।8, USA

Tel +I 27079882 I 8 (office)

$\mathrm{Tel}+$ I 2707988900 (clinic)

Mob +| $20243 \mid 7766$

Email courtney.m.crawford@us.army.mil
Context: The purpose of this study was to conduct a quality improvement (QI), applied practical review of the American Joint Committee on Cancer (AJCC) 7th edition, Carcinoma of the Eyelid staging system. AJCC utilizes a primary tumor, lymph node, metastasis (pTNM) cancer staging approach.

Objective: We wanted to determine if the AJCC pTNM carcinoma staging system identified patients with highly aggressive carcinoma of the eyelid. We also wanted to determine if there were any unexpected issues in its practical application.

Design: We conducted a 15-year, consecutive, retrospective review of all cases of excisional biopsy for carcinoma of the eyelid. We reviewed the original histopathology slides and complete pathology records for each case.

Results: Over a 15-year review period, 52 cases of excisional biopsy for carcinoma of the eyelid were identified. The average age of the study population was 72 years. Nodular welldifferentiated basal cell carcinoma (BCC) was the predominant histology for $85 \%$ of cases. Morpheaform/metatypical BCC was the next dominant at 9\%. Squamous cell carcinoma and sebaceous carcinoma followed at $4 \%$ and $2 \%$, respectively. We were able to assign clear staging to 50 of the 52 cases with the available pathology data. The stage results were as follows: stage 1A $72 \%$, stage 1B $22 \%$, stage II $4 \%$, stage III $2 \%$, with no cases of stage IV metastatic disease.

Conclusions: The 7th edition AJCC Carcinoma of the Eyelid chapter proved to be a practical tool for carcinoma staging of the eyelid. The largest tumor dimension remains an effective predictive factor. High-grade pathologic prognostic factors such as tumor necrosis or perineural spread had a $100 \%$ association with a final stage of II or greater. Concordance and compliance was $100 \%$ for the recommended site-specific pathologic risk factors. Regarding squamous cell carcinoma of the eyelid, three new required data points had a $0 \%$ reporting rate over 15 years. Overall, smaller less invasive tumors were classified as stage 1A and 1B tumors. More invasive and higher risk tumors fell into appropriate higher staging classifications. The newly recommended prognostic site-specific tumor factors appear to work well with a high concordance with staging severity, and strong medical community acceptance.

Keywords: eyelid, pathology, oncology

\section{Introduction}

The purpose of this study was to conduct a quality improvement (QI), applied practical review of the American Joint Committee on Cancer (AJCC) 7th edition, carcinoma of the eyelid staging system. AJCC utilizes a primary tumor, lymph node, metastasis (pTNM) cancer staging approach. ${ }^{1}$ This QI study was not sponsored by the AJCC. We wanted to determine if the AJCC pTNM carcinoma staging system identified 
patients with highly aggressive carcinoma of the eyelid. We also wanted to determine if there were any unexpected issues in its practical application. In short, does it work, are there glitches, and is it effective? In a quality improvement process, results are not just data. Results give us better understanding of the tools we use every day, and the potential for their improvement in the future.

Cancer staging systems have an inherent tension, a dynamic balance between pathologic features and clinical staging. ${ }^{2}$ Questions arise out of this tension and balance. In our case, do medial canthal tumors require a distinct prognostic factor status? Does this staging system work for its intended target audience? We tested these issues through a quality improvement approach. We applied the current cancer staging system to a consecutive group of eyelid carcinoma cases over a 15-year time span. This time span began on January 1, 1990 and ended on January 1, 2005.

Similar tensions between pathologic findings and clinical evaluation have arisen in a number of areas in oncology and cancer staging. ${ }^{1-14}$ McLean et al published a multivariate analysis regarding ciliary body location of uveal melanoma. ${ }^{3}$ Numerous clinical studies showed an increased metastatic risk with clinically diagnosed ciliary body melanoma. Ciliary body tumors in the AFIP database had a worse prognosis. When compared to pathologic features including largest tumor dimension and tumor cell type in a multivariate analysis, the results were the same. Instead of disproving one camp or another, it showed that the data could be used equally from different perspectives. ${ }^{4-14}$ This is a very similar concept to our clinical question of medial canthal tumors.

\section{Methods and materials}

We conducted a 15-year, consecutive, retrospective review of all cases of excisional biopsy for carcinoma of the eyelid. We reviewed the original histopathology slides and pathology records for each case. Our pathology working draft document contains the gross description of a current case and all pathology specimens dating back to January 1, 1990. Thus for each case we obtained the original excisional glass slides, a pathology working draft, and the pathology final diagnosis sheet for staging review. Data collection was limited to staging data available in the original documents and description only. We verified the data but did not collate new features.

In order to facilitate clinical investigations approval, we limited our data collection to reduce exposure to protected patient health information. Very early in the study we were able to redact any information such as name, race, date of birth, or any similar identifying information. Data points collected did include: age, surgical number, largest tumor dimension, derived stage with a pTNM current classification, histology, grade, prognostic factors, and required factors as listed in the 7th edition Carcinoma of the Eyelid chapter. We also obtained location with specific awareness of medial and lateral canthus, and the total number of skin and visceral carcinomas.

We approached the study as a quality improvement effort. As such there was internal and external review to limit such factors as selection bias or predetermined findings.

\section{Results}

Over a 15-year review period, 52 cases of excisional biopsy for carcinoma of the eyelid were identified. The average age of the study population was 72 years. Nodular welldifferentiated basal cell carcinoma (BCC) was the predominant histology for $85 \%$ of cases. Morpheaform/metatypical BCC was the next most dominant at $9 \%$. Squamous cell carcinoma and sebaceous carcinoma followed at $4 \%$ and $2 \%$, respectively.

We were able to assign clear staging to 50 of the 52 cases with the available pathology data. Two cases, referred to Mohs surgery, did not have a recorded pathology database for complete staging. For the remaining 50 cases, the stage results were as follows: stage $1 \mathrm{~A} 72 \%$, stage 1B $22 \%$, stage II $4 \%$, stage III $2 \%$, with no cases of stage IV metastatic disease.

Medial and lateral canthal tumors represented $18 \%$ of the cases. The staging distribution was very similar to the overall study distribution.

High-risk prognostic factors including tumor necrosis, perineural spread, pagetoid spread, and multiple carcinoma syndromes such as Muir-Torre syndrome, had an $80 \%$ association with tumors staged at $1 \mathrm{~B}$ and higher, and a 100\% association with all tumors greater than or equal to stage II. The high-risk prognostic factors recorded in original pathology reports were present on QI review, with 100\% compliance and concordance. This was confirmed by two pathologists looking at the original glass slides in quality assurance and our subsequent QI review.

Prognostic features fall into two categories in the 7 th edition chapter on eyelid carcinoma staging, recommended and required. ${ }^{4}$ Prognostic factors (site specific factors) are designated as recommended for collection. They include pathologic features such as tumor necrosis, or pagetoid spread, and clinical features such as a history of HIV or multiple carcinoma syndromes. Of the prognostic factors recommended for collection by the 7 th edition, $100 \%$ of the factors required 
for staging were identified in the recorded pathologic report, and concordant with the findings of this study.

In the 7th edition, squamous cell carcinoma of the eyelid is the only subset, with more stringent prognostic dataset designated as "required for staging". ${ }^{1}$ In this subset the data compliance in the original report was highly disparate. Some features such as grade and presence or absence of perineural invasion had a $100 \%$ reporting concordance. Other features, such as Clark's level, tumor thickness in mm, and a statement that the tissue was not derived from the ear or non-hairy lip had $0 \%$ reporting. Staging for these two cases of squamous cell carcinoma was based on the 6th edition criteria.

The average primary tumor dimension was $3.75 \mathrm{~mm}$. The average number of pathologically confirmed skin carcinomas and visceral carcinomas was $2.4 \%$ and $0.3 \%$ per patient, respectively. The retrospective review of all pathologic tissues on file dated back to January of 1990 for all patients and specimens.

\section{Discussion}

All clinicians and pathologists can relate to the importance of communication. The tissue submission form for pathologic diagnosis requires all vital data. The communication process must be clear, concise, and simple to maximize the number of teams that can use the data. pTNM classification is a common language that can assist this process. ${ }^{1,5,7-13}$ The level of assistance is dependent upon an understanding of the limits and applications that can be highlighted by such a review.

The AJCC 7th edition Carcinoma of the Eyelid chapter was found to be an effective tool for identifying patients with aggressive tumors. ${ }^{1}$ As authors, the following questions came to light while conducting this QI exercise:

- Do medial canthal tumors represent a unique subset worthy of a prognostic value designation?

- What measurement is utilized to determine largest tumor dimension (LTD)?

- Does the objective in grossing eyelid carcinoma for margins, change the measurement of LTD?

- What were the recurrent carcinoma rates at the same site?

- What do we do with Mohs specimens?

- Why is there such a high noncompliance rate for the newly required data section under squamous cell carcinoma of the eyelid?

Do medial canthal tumors represent a unique subset of carcinomas of the eyelid? A number of studies have identified this location as an independent clinical risk factor. Our numbers were too small to answer this question and our patient population may have more access to care, avoiding tumors that invade into deeper tissue planes.

High-grade pathologic prognostic factors had a much higher association and direct association with higher staging values. These two features may be complementary rather than in competition. The fact that medial canthal tumors were strongly represented in the submitted data indicates the surgeons consider this a factor and supply the data in current collection formats.

We utilized recorded data for largest tumor dimension only based upon pathologically written documents and the original glass slides. If the measurement was not recorded as part of the gross, or provided as clinical data by the surgeon, we utilized measurement from the glass slides. This is a realworld limitation that is similar to what a tumor registrar may face. Unlike whole eyes with solid tumors such as choroidal melanoma, the eyelid contracts as soon as it is resected off the patient.

Our average largest tumor dimension was $3.75 \mathrm{~mm}$. This was measured by glass slide in $100 \%$ of cases. As the principal submitting surgeon, I consider this to be approximately $50 \%$ smaller than expected. There are a number of reasons for this disparity. Ensuring surgical margins are free of tumors is a principal objective for the pathologist in grossing an eyelid carcinoma specimen. ${ }^{1,6}$ This objective alters the pathologic incisions used to sample the tissue. Unlike choroidal melanoma, defining the largest tumor dimension may not be the primary consideration for sectioning. ${ }^{3}$ This does not mean that pTNM systems don't work for adnexal tissues of the eye, it is just a reality check on how data is obtained and may be available to a tumor registrar.

We had a $4 \%$ tumor recurrence rate. One case was from the 50 cases that underwent oculoplastics approach resection. One case was from a total of two Mohs surgical resections. Because two cases referred to Mohs surgery did not have necessary pathology data, it may be preferable to stage carcinomas prior to performing Mohs surgery.

The prognostic features adapted in the 7 th edition under "recommend risk factors" appear to have a high acceptance within our military hospital setting. ${ }^{1}$ The reporting rate was $100 \%$. Our pathologists have trained in a variety of dermatopathology, surgical pathology, general pathology, and ophthalmic pathology institutions. This QI study spanned the reporting habits of a diverse group of pathologists over 15 years. They are all associated with the same military system.

The compliance rate for the squamous cell carcinoma of the eyelid, requiring prognostic features, was widely varied. 
There was $100 \%$ reporting for such features as tumor grade or pathologic risk factors such as perineural spread. However, the newest required features - Clark's level, tumor thickness in $\mathrm{mm}$, and statement that the tissue was not derived from the ear or non-hairy lip - had $0 \%$ compliance. No final pathologic diagnostic reports listed a Clark's level for eyelid SCC. No reports listed tumor thickness in $\mathrm{mm}$, and no reports included a statement that the tumor did not come from the ear or non-hairy lip. These are all required fields in the 7 th edition. ${ }^{1}$ It appears the groundwork for introducing such items did not gain sufficient general or dermatopathology support to begin its approach as a "required" field. The newly required site-specific factors have features that may result in a low reporting value within the general pathology community. ${ }^{1,2,6}$

Overall, the 7th edition AJCC Carcinoma of the Eyelid chapter proved to be a practical tool for carcinoma staging of the eyelid. We learned there may be disparate findings on largest tumor dimension. Yet largest tumor dimension remains an effective predictive factor particularly as it is supported by the remainder of the 7 th edition staging features. Smaller less invasive tumors were classified as stage $1 \mathrm{~A}$ and $1 \mathrm{~B}$ tumors. Much more invasive and higher risk tumors fell into appropriate higher staging classifications. Our pathologist had no difficulty understanding T4 in its current definition. However it may be clearer to define T4 as a radical excision with positive margins. The newly recommended prognostic site-specific tumor factors appear to work well with a high concordance with staging severity and strong medical community acceptance.

\section{Disclosure}

The authors declare no conflicts of interest in relation to this paper.

\section{References}

1. Carcinoma of the eyelid. In: Edge SE, Byrd DR, Carducci MA, Compton CA, editors. AJCC Cancer Staging Manual. 7th Ed. New York: Springer; 2010.

2. Barta RS, Kelley LC. A risk scale for predicting extensive subclinical spread of nonmelanoma skin cancer. Dermatol Surg. 2002;28(2): 107-112; discussion 112.

3. McLean IW, Ainbinder DJ, Gamel JW, McCurdy JB. Choroidal-ciliary body melanoma: A multivariate analysis of tumor location. Ophthalmology. 1995;102(7):1060-1064.

4. Dequanter D, Lothaire P, Bourgeois P, Flamen P, Lemort M, Andry G. Sentinel lymph node evaluation in squamous cell carcinoma of the head and neck cancer: preliminary results. Acta Chir Belg. 2006;106:519-522.

5. Allen PJ, Bowne WB, Jaques DP, Brennan MF, Busam K, Coit DG. Merkel Cell Carcinoma: Prognosis and treatment of patients from a single institution. J Clin Oncol. 2005;23:2300-2309.

6. Nemet AY, Deckel Y, Martin PA, et al. Management of periocular basal and squamous cell carcinoma: a series of 485 cases. Am J Ophthalmol. 2006;142(2):293-297.

7. Betis F, Hofman V, Lagier J, Gastaud P, Santini J, Hofman P. Primary signet ring cell carcinoma of the Eccrine sweat gland in the eyelid. Immunohistochemical and ultrastructural study of a case. $J$ Fr Ophtalmol. 2002;25(5):547-551. French.

8. Ducasse A, Pluot M, Gotzamanis A, Brugniart C, Leccia L, Rossi P. Factors of recurrence of basal cell carcinomas of the eyelid. $\mathrm{J} \mathrm{Fr} \mathrm{Oph-}$ talmol. 2002;25(5):512-516. French.

9. El-Domeiri AA, Brasfield RD, Huvos AG, Strong EW. Sweat gland carcinoma: A clinico-pathologic study of 83 patients. Ann Surg. 1971;173(2):270-274.

10. Esmaeli B, Naderi A, Hidaji L, Blumenschein G, Prieto VG. Merkel cell carcinoma of the eyelid with a positive sentinel node. Arch Ophthalmol. 2002;120(5):646-648.

11. Faustina M, Diba R, Ahmadi MA, Esmaeli B. Patterns of regional and distant metastasis in patients with eyelid and periocular squamous cell carcinoma. Ophthalmology. 2004;111(10):1930-1932.

12. Rao NA, Hidayat AA, McLean IW, Zimmerman LE. Sebaceous carcinomas of the ocular adnexa: A clinicopathologic study of 104 cases, with five-year follow-up data. Hum Pathol. 1982;13(2):113-122.

13. Soysal HG, Markoc F. Invasive squamous cell carcinoma of the eyelids and periorbital region. Br J Ophthalmol. 2007;91(3):325-329.

14. Yiengpruksawan A, Coit DG, Thaler HT, Urmacher C, Knapper WK. Merkel cell carcinoma: prognosis and management. Arch Surg. 1991;126(12):1514-1519.
Clinical Ophthalmology

\section{Publish your work in this journal}

Clinical Ophthalmology is an international, peer-reviewed journal covering all subspecialties within ophthalmology. Key topics include: Optometry; Visual science; Pharmacology and drug therapy in eye diseases; Basic Sciences; Primary and Secondary eye care; Patient Safety and Quality of Care Improvements. This journal is indexed on Submit your manuscript here: http://www.dovepress.com/clinical-ophthalmology-journal

\section{Dovepress}

PubMed Central and CAS, and is the official journal of The Society of Clinical Ophthalmology (SCO). The manuscript management system is completely online and includes a very quick and fair peer-review system, which is all easy to use. Visit http://www.dovepress.com/ testimonials.php to read real quotes from published authors. 